\title{
CRESCIMENTO E EFICIÊNCIA NA UTILIZAÇÃO DE NUTRIENTES EM PLANTAS JOVENS DE EUTERPE EDULIS MART. SOB DOIS NÍVEIS DE IRRADIÂNCIA, NITROGÊNIO E FÓSFORO
}

\author{
Rafael Illenseer ${ }^{1}$ \\ Maria Terezinha Silveira Paulilo²
}

Recebido em 02/10/2000. Aceito em 23/03/2002.

\begin{abstract}
RESUMO - (Crescimento e eficiência na utilização de nutrientes em plantas jovens de Euterpe edulis Mart. sob dois níveis de irradiância, nitrogênio e fósforo). $\mathrm{O}$ crescimento e a eficiência na utilização de nutrientes foram determinados para plantas jovens de Euterpe edulis Mart. cultivadas em dois níveis de irradiância (50\% e 2\% da luz solar, com irradiância máxima de 900 e $36 \mu \mathrm{mol}$ de fótons $\mathrm{m}^{-2} \mathrm{~s}^{-1}$, respectivamente) e dois níveis de nitrogênio $\left(56,1\right.$ e $\left.6,5 \mathrm{mg} \mathrm{L}^{-1}\right)$ e fósforo $\left(10,0\right.$ e 2,0 $\left.\mathrm{mg} \mathrm{L}^{-1}\right)$. O nível de irradiância afetou o crescimento de plantas, sendo que plantas sob menor irradiância apresentaram menor crescimento. Sob maior suprimento de nutrientes as plantas apresentaram maior biomassa apenas sob maior irradiância. Maior suprimento de nitrogênio ou fósforo isoladamente não proporcionou crescimento semelhante àquele verificado em plantas sob maior suprimento conjunto dos dois nutrientes. A eficiência na utilização de nitrogênio (EUN) aumentou com menor suprimento de nitrogênio independentemente do regime de luz. A eficiência na utilização de fósforo (EUP) aumentou com o aumento da irradiância, mas não foi influenciada pelos níveis de fósforo. Os dados encontrados para E. edulis sugerem que para esta espécie 1) é improvável que a variação de nitrogênio e fósforo limite o crescimento de plantas jovens sob o dossel da floresta, o nível de irradiância parece antes ser o principal fator limitante do crescimento destas plantas neste ambiente, 2) o desempenho de plantas jovens pode ser favorecido pelo aparecimento de clareiras em função da plasticidade destas plantas em aumentar tanto a eficiência na utilização de nutrientes como a taxa de assimilação líquida de carbono em maior irradiância, 3) a maior eficiência na utilização de nitrogênio em menor oferta deste nutriente pode aumentar a competitividade de plantas jovens em ambientes com baixa oferta deste nutriente e 4) em alta irradiância, tanto a baixa disponibilidade de fósforo quanto a de nitrogênio pode inibir o crescimento de plantas jovens no campo .
\end{abstract}

Palavras-chave - Euterpe edulis, crescimento, nitrogênio, fósforo, luz

\begin{abstract}
Growth and nutrient use efficiency in Euterpe edulis Mart. seedlings under two levels of irradiance, nitrogen and phosphorus). Growth and nutrient use efficiency were determined for Euterpe edulis Mart. seedlings grown under two levels of irradiance $2 \%$ and $50 \%$ of full sun, with the peak radiation flux values of 36 and $900 \mu \mathrm{mol}$

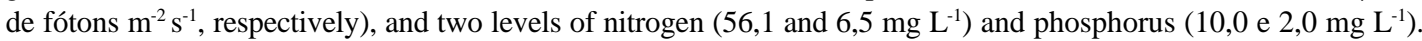
Seedlings grown under low irradiance supply had less biomass. Higher supply of both nitrogen and phosphorus had a significant effect on total biomass only in plants grown under high irradiance. Only a higher nitrogen supply or only a higher phosphorus supply didn't affect the growth in higher irradiance. Nitrogen use efficiency (NUE) and phosphorus use efficiency (PUE) increased with increased supply of irradiance. NUE increased with low supply of nitrogen. These results suggest that for E. edulis 1) it is unlikely that natural variation in nitrogen or phosphorus availability will affect the growth of seedlings in the understorey environment, as the availability of irradiance rather
\end{abstract}

\footnotetext{
${ }^{1}$ Bolsista CNPq.

${ }^{2}$ Departamento de Botânica, UFSC, CEP 88040-900, Florianópolis, SC.
} 
than major soil nutrients seems to be the limiting factor for the growth of seedlings in this environment, 2) the seedlings can take benefit from gap appearance since they can adjust their growth and nutrient use efficiency when light and nutrient availability are varied, 3) the higher NUE showed by the seedlings under low nitrogen supply can enhance their ability for competition under environments with low nitrogen supply and 4) at a high irradiance the availability of both nitrogen and phosphorus can limit the growth of seedlings in the field.

Key words - Euterpe edulis, growth, light, nitrogen, phosphorus

\section{Introdução}

Euterpe edulis é uma espécie do estrato médio da Floresta Tropical Atlântica, de alto valor econômico como alimento, sofrendo, em virtude disto, intenso extrativismo, o que vem comprometendo sua regeneração natural (Reis et al. 1996). Dados sobre a ecofisiologia de $E$. edulis, principalmente o comportamento em relação à luz e à utilização de nutrientes, fatores que têm papel fundamental na regeneração de espécies (Kitajima 1996; Koerselman \& Meuleman 1996), são de primordial importância para orientar tanto a regeneração artificial, como programas de manejo para E. edulis.

A disponibilidade de luz para as plântulas nas florestas tropicais úmidas é bastante heterogênea, variando no tempo e no espaço. $\mathrm{Na}$ floresta fechada, apenas cerca de 0,5 a $2 \%$ da luz solar alcança o chão da floresta (Clark et al. 1996), tornando o crescimento de muitas plântulas no interior da floresta limitado pela escassez de luz. Por outro lado, o aparecimento de clareiras tem grande papel no crescimento de plântulas, pois aumenta a quantidade de luz num determinado trecho da floresta, levando à variação de outros fatores, como a atividade de microorganismos, a umidade do solo e a taxa de mineralização da matéria orgânica, afetando, com isto, a disponibilidade de nutrientes (Kitajima 1996; Minotta \& Pinzauti 1996).

Com alteração do regime de luz ou nutricional, as espécies costumam mostrar alterações morfo-fisiológicas para maximizar o ganho de massa seca nas novas condições. Entre estas alterações morfo-fisiológicas estão variações na distribuição de biomassa entre raiz e parte aérea, na taxa de assimilação líquida de carbono, na razão de área foliar (Osunkoya et al. 1994) e no aproveitamento e eficiência de utilização de nutrientes (Elliot \& White 1994). Sob regime de luz não limitante as espécies tendem a favorecer o crescimento de raiz, a apresentar maiores taxas de crescimento e de assimilação líquida de carbono (Osunkoya et al. 1994), a aproveitar melhor um aumento nutricional (Peace $\&$ Grubb 1982), enquanto que a eficiência na utilização de nutrientes varia com a espécie e o nutriente avaliado (Elliot \& White 1994). Sob regimes nutricionais não limitantes as espécies, normalmente, apresentam maior crescimento, menor razão raiz/parte aérea (Gunatilleke et al. 1997) e menor eficiência na utilização de nutrientes (Shaver \& Melillo 1984).

O objetivo deste trabalho foi verificar, em plantas jovens de E. edulis, a resposta em crescimento e eficiência na utilização de nitrogênio e fósforo quando se varia a disponibilidade de luz e desses dois nutrientes. $\mathrm{O}$ estudo foi feito variando a quantidade de nitrogênio e fósforo, uma vez que estes são os nutrientes que mais limitam a produção vegetal tanto na agricultura como em sistemas florestais (Schachtman et al. 1998). As duas condições de luz empregadas, $2 \%$ e $50 \%$ da irradiância solar plena, foram escolhidas por serem as irradiâncias encontradas sob dossel da floresta, ambiente de ocorrência natural da espécie (Reis et al. 1996).

\section{Material e métodos}

Frutos de Euterpe edulis Mart., provenientes de plantas localizadas na região de Floresta Atlântica da Ilha de Santa Catarina, foram 
despolpados através de fricção manual e colocados para germinar em sacos plásticos fechados levemente umedecidos. Quando o epicótilo emergido das sementes atingiu cerca de $2,5 \mathrm{~cm}$, as plântulas foram colocadas em sacos plásticos de $20 \mathrm{~cm}$ de comprimento por $7 \mathrm{~cm}$ de diâmetro, perfurados na base, contendo uma mistura de argila e areia na proporção de 1:2.

As plântulas foram submetidas a dois níveis de luz e a dois níveis de nitrogênio e fósforo. Os níveis de luz foram dados cultivando as plantas sob caixas confeccionadas com telas de polietileno de cor preta (sombrite), permitindo a passagem de 50\% ou $2 \%$ de irradiância solar, correspondendo à irradiância máxima de 900 e $36 \mu$ mol de fótons $\mathrm{m}^{-2}$ $\mathrm{s}^{-1}$, respectivamente. As caixas de sombrite foram colocadas a céu aberto, de maneira a evitar o auto sombreamento, em área pertencente ao Departamento de Botânica da Universidade Federal de Santa Catarina. A densidade do fluxo de fótons fotossintéticos no local do experimento, foi quantificada através de um quantômetro LICOR 250 , a céu aberto, ao meio dia de um dia claro próximo ao solstício de verão, sendo de $1800 \mu \mathrm{mol}$ de fótons $\mathrm{m}^{-2} \mathrm{~s}^{-1}$. $\mathrm{O}$ corte de luz dado pelas telas sombrite foi determinado tomando-se a densidade de fluxo de fótons a pleno sol e sob as telas sombrite, calculando-se, então, a porcentagem de corte de luz. Os dois níveis de nitrogênio (56,1 e 6,5 $\left.\mathrm{mg} \mathrm{L}^{-1}\right)$ e fósforo $(10,0 \mathrm{e}$ 2,0 $\mathrm{mg} \mathrm{L}^{-1}$ ) foram dados através de soluções nutritivas descritas na tabela 1 . As plântulas foram divididas em 6 lotes de 50 plântulas, cada lote recebendo, por 207 dias, entre os meses de novembro a maio, um dos tratamentos abaixo: $\left(\mathrm{C}_{50}\right): 900 \mu \mathrm{mol}$ de fótons $\mathrm{m}^{-2} \mathrm{~s}^{-1}$ de irradiância máxima, $56,1 \mathrm{mg} \mathrm{L}^{-1}$ de nitrogênio e $10,0 \mathrm{mg} \mathrm{L}^{-1}$ de fósforo.

$\left(-\mathrm{P}_{50}\right): 900 \mu \mathrm{mol}$ de fótons $\mathrm{m}^{-2} \mathrm{~s}^{-1}$ de irradiância máxima, $56,1 \mathrm{mg} \mathrm{L}^{-1}$ de nitrogênio e $2,0 \mathrm{mg} \mathrm{L}^{-1}$ de fósforo.

$\left(-\mathrm{N}_{50}\right): 900 \mu \mathrm{mol}$ de fótons $\mathrm{m}^{-2} \mathrm{~s}^{-1}$ de irradiância máxima, $6,5 \mathrm{mg} \mathrm{L}^{-1}$ de nitrogênio e $10,0 \mathrm{mg} \mathrm{L}^{-1}$ de fósforo.
$\left(\mathrm{C}_{2}\right): 36 \mu \mathrm{mol}$ de fótons $\mathrm{m}^{-2} \mathrm{~s}^{-1}$ de irradiância máxima, $56,1 \mathrm{mg} \mathrm{L}^{-1}$ de nitrogênio e $10,0 \mathrm{mg} \mathrm{L}^{-1}$ de fósforo.

$\left(-\mathrm{P}_{2}\right): 36 \mu \mathrm{mol}$ de fótons $\mathrm{m}^{-2} \mathrm{~s}^{-1}$ de irradiância máxima, $56,1 \mathrm{mg} \mathrm{L}^{-1}$ de nitrogênio e $2,0 \mathrm{mg} \mathrm{L}^{-1}$ de fósforo.

$\left(-\mathrm{N}_{2}\right): 36 \mu \mathrm{mol}$ de fótons $\mathrm{m}^{-2} \mathrm{~s}^{-1}$ de irradiância máxima, $6,5 \mathrm{mg} \mathrm{L}^{-1}$ de nitrogênio e $10,0 \mathrm{mg} \mathrm{L}^{-1}$ de fósforo.

As plântulas foram irrigadas, até percolação, com solução de seu respectivo tratamento a cada 15 dias e com água destilada no intervalo entre duas irrigações consecutivas com solução nutritiva.

A área foliar das plantas foi obtida através da comparação do peso do contorno das folhas desenhadas em papel com o peso de áreas conhecidas do mesmo papel. A massa seca de partes segmentadas das plantas foi obtida utilizando-se balança analítica após a secagem do material por $48 \mathrm{~h}$ a $80^{\circ} \mathrm{C}$.

A taxa média de crescimento relativo (TCR), a taxa média de assimilação líquida (TAL) e a razão média de área foliar (RAF) foram calculadas, segundo Hunt (1982), através das fórmulas: $\mathrm{TCR}=\left(\ln \mathrm{M}_{2}-\ln \mathrm{M}_{1}\right) /\left(\mathrm{T}_{2}-\mathrm{T}_{1}\right)$; $\mathrm{TAL}=\left(\mathrm{M}_{2}-\mathrm{M}_{1}\right)\left(\ln \mathrm{A}_{2}-\ln \mathrm{A}_{1}\right) /\left(\mathrm{T}_{2}-\mathrm{T}_{1}\right)\left(\mathrm{A}_{2}-\right.$ $\left.\mathrm{A}_{1}\right)$ e $\mathrm{RAF}=\left[\left(\mathrm{A}_{1} / \mathrm{M}_{1}\right)+\left(\mathrm{A}_{2} / \mathrm{M}_{2}\right)\right] / 2$; onde $\mathrm{M}_{1}$ = massa seca total após 74 dias de crescimento nos diferentes tratamentos (coleta 2) e $\mathrm{M}_{2}=$ massa seca das plantas após 207 dias de crescimento nos diferentes tratamentos (coleta 3), $T_{2}-T_{1}=$ intervalo de tempo entre as coletas 2 e 3; e $A_{1}$ e $A_{2}=$ área foliar das plantas nas coletas 2 e 3 , respectivamente.

A eficiência no uso de nutrientes foi calculada pela fórmula $\left(\mathrm{M}_{2}-\mathrm{M}_{1}\right) /$ conteúdo total de nutrientes em $\mathrm{M}_{2}$, segundo Elliot \& White (1994), onde $\mathrm{M}_{1}=$ massa seca total das plantas antes do início dos tratamentos (coleta 1) e $\mathrm{M}_{2}=$ massa seca das plantas após 207 dias de crescimento nos diferentes tratamentos (coleta 3 ).

Os teores de minerais no material vegetal foram determinados, segundo Tedesco et al. 
(1995). O teor de nitrogênio foi determinado por titulação e o de fósforo por colorimetria, após digestão do tecido vegetal seco em bloco digestor usando ácido sulfúrico e solução de peróxido de hidrogênio, contendo como resíduo menos que 2ppm de fósforo, quantidade desprezível na determinação de fósforo.

O número de plantas utilizado para as medidas de massa seca, área foliar e análise de crescimento foi de nove por tratamento. Para a análise de nutrientes no tecido foram utilizadas três plantas por tratamento e três repetições por planta. Os dados do experimento fatorial $(2 \times 2 \times 2)$ foram comparados através da análise de variância seguida do teste de Tukey a 5\%, segundo Banzato \& Kronka (1989).

\section{Resultados}

Plantas submetidas à maior irradiância apresentaram maior razão raiz:parte aérea (R:PA), maior massa seca (Tab. 2), maior TCR e TAL médias e menor RAF média (Tab. 3) que plantas submetidas à menor irradiância, independentemente do tratamento nutricional dado. A maior área foliar apresentada foi em plantas sob maior irradiância e sem limitação de nutrientes; em plantas sob maior irradiância a deficiência de nitrogênio e fósforo diminuíram a área foliar, mas em plantas sob menor irradiância, apenas a deficiência de nitrogênio diminuiu a área foliar (Tab. 2). Deficiência de nitrogênio ou fósforo só afetou o crescimento de plantas sob maior irradiância, causando diminuição de massa seca (Tab. 2). A R:PA não foi alterada pelo tratamento nutricional em plantas sob menor irradiância; sob maior irradiância a R:PA foi menor sob deficiência de fósforo que sob deficiência de nitrogênio (Tab. 2). Deficiências de nitrogênio e fósforo diminuíram a TCR e a TAL em plantas sob maior irradiância, mas não tiveram efeito na RAF de plantas em quaisquer dos tratamentos de irradiância (Tab. 3).

A eficiência na utilização de nitrogênio (EUN) e fósforo (EUP) foi maior em plantas submetidas a maiores irradiâncias (Tab. 4). Sob baixo teor de nitrogênio, as plantas apresentaram maior EUN, independentemente da irradiância recebida. Baixo teor de fósforo não influenciou a EUP ou a EUN em nenhuma das irradiâncias (Tab. 4).

A porcentagem de fósforo em relação à massa seca da planta não foi afetada nem pelo tratamento de irradiância, nem pelo tratamento nutricional. O conteúdo total de fósforo, entretanto, sofreu influência dos tratamentos dados: foi maior em plantas submetidas conjuntamente à maior irradiância e maior nutrição mineral, diminuiu em plantas sob deficiência de fósforo ou de nitrogênio quando em maior irradiância e não foi afetado pelo nível de nutrientes em plantas menor irradiância (Tab. 5).

A porcentagem nitrogênio em relação à massa seca da planta foi menor em plantas sob maior irradiância $(0,96$ a 1,22\%) que em plantas sob menor irradiância $(1,43$ a $1,87 \%)$. A deficiência de nitrogênio diminuiu a porcentagem de nitrogênio em plantas sob maior ou menor irradiância. O conteúdo de nitrogênio total em plantas sem deficiência nutricional foi maior em maior irradiância $\left(14,5 \mathrm{mg} \mathrm{planta}^{-1}\right)$ que sob menor irradiância $\left(7,5 \mathrm{mg}\right.$ planta $\left.^{-1}\right)$. A deficiência de nitrogênio diminuiu o conteúdo de nitrogênio por planta em quaisquer dos tratamentos de irradiância (Tab. 5).

Considerando raiz e parte aérea separadamente, as concentrações de nitrogênio e fósforo foram diferentes em raiz e parte aérea, havendo mais nitrogênio e menos fósforo na parte aérea que na raiz, independentemente do regime de luz (Tab. 6).

\section{Discussão}

$\mathrm{Na}$ maioria das espécies de florestas tropicais, a baixa irradiância existente sob o dossel da floresta fechada limita o crescimento de plantas, sendo que as espécies só alcançam seu desenvolvimento pleno com o aumento da irradiância, o qual pode ocorrer através do 
Tabela 1. Composição das soluções nutritivas aplicadas às plântulas de Euterpe edulis.

\begin{tabular}{|c|c|c|c|}
\hline Soluções empregadas & $\mathrm{C}$ & $\begin{array}{l}-\mathrm{N} \\
\mathrm{mol} \mathrm{m} \mathrm{m}^{-3}\end{array}$ & $-\mathrm{P}$ \\
\hline \multicolumn{4}{|l|}{ Macronutrientes } \\
\hline $\mathrm{KNO}_{3}$ & 1,00 & 0,20 & 1,00 \\
\hline $\mathrm{Na}_{2}\left(\mathrm{HPO}_{4}\right)$ & 0,25 & 0,25 & 0,05 \\
\hline $\mathrm{NH}_{4}\left(\mathrm{NO}_{3}\right)$ & 1,50 & - & 1,50 \\
\hline $\mathrm{MgSO}_{4}$ & 1,00 & 1,00 & 1,00 \\
\hline $\mathrm{CaSO}_{4}$ & 0,50 & 0,50 & 0,50 \\
\hline $\mathrm{KCl}$ & - & 0,80 & - \\
\hline \multicolumn{4}{|l|}{ Micronutrientes } \\
\hline $\mathrm{H}_{3} \mathrm{BO}_{3}$ & 0,00625 & 0,00625 & 0,00625 \\
\hline $\mathrm{MnSO}_{4} .7 \mathrm{H}_{2} \mathrm{O}$ & 0,00050 & 0,00050 & 0,00050 \\
\hline $\mathrm{ZnSO}_{4} \cdot 7 \mathrm{H}_{2} \mathrm{O}$ & 0,00050 & 0,00050 & 0,00050 \\
\hline $\mathrm{CuSO}_{4} .5 \mathrm{H}_{2} \mathrm{O}$ & 0,000125 & 0,000125 & 0,000125 \\
\hline $\mathrm{H}_{2} \mathrm{MoO}_{4}$ & 0,000125 & 0,000125 & 0,000125 \\
\hline $\mathrm{CoCl}_{2}$ & 0,00190 & 0,00190 & 0,00190 \\
\hline NaFeDTPA & 0,02700 & 0,02700 & 0,00270 \\
\hline
\end{tabular}

$\mathrm{C}=56,1 \mathrm{mg} \mathrm{L}^{-1}$ de nitrogênio - 32,6 $\mathrm{mg} \mathrm{L}^{-1}$ na forma de $\mathrm{KNO}_{3}$ e 23,5 $\mathrm{mg} \mathrm{L}^{-1}$ na forma de $\mathrm{NH}_{4} \mathrm{NO}_{3}$ ) e $10,0 \mathrm{mg} \mathrm{L}^{-1}$ de fósforo na forma de $\mathrm{Na}_{2}\left(\mathrm{HPO}_{4}\right) ;-\mathrm{N}=6,5 \mathrm{mg} \mathrm{L}^{-1}$ de nitrogênio na forma de $\mathrm{KNO}_{3}$ e $10,0 \mathrm{mg} \mathrm{L}^{-1}$ de fósforo e $-\mathrm{P}=56,1 \mathrm{mg} \mathrm{L} \mathrm{L}^{-1}$ de nitrogênio e $2,0 \mathrm{mg} \mathrm{L}^{-1}$ de fósforo.

Tabela 2. Massa seca (MS), área foliar e razão raiz:parte aérea (R:PA) de plantas de Euterpe edulis após 207 dias crescendo a $50 \%$ e $2 \%$ da irradiância solar plena, irrigadas com solução nutritiva com alto e baixo teores de fósforo e nitrogênio.

\begin{tabular}{lccccc}
\hline Tratamento & $\begin{array}{c}\text { MS Total } \\
(\mathrm{mg})\end{array}$ & $\begin{array}{c}\text { MS Raiz } \\
(\mathrm{mg})\end{array}$ & $\begin{array}{c}\text { MS Parte Aérea } \\
(\mathrm{mg})\end{array}$ & $\begin{array}{c}\text { Área Foliar } \\
\left(\mathrm{cm}^{2}\right)\end{array}$ & R:PA \\
\hline $\mathrm{C}_{50}$ & $1223,00 \mathrm{a}$ & $493,67 \mathrm{a}$ & $730,44 \mathrm{a}$ & $99,82 \mathrm{a}$ & $0,69 \mathrm{ab}$ \\
$-\mathrm{P}_{50}$ & $849,33 \mathrm{~b}$ & $344,22 \mathrm{~b}$ & $505,11 \mathrm{~b}$ & $77,13 \mathrm{~b}$ & $0,58 \mathrm{~b}$ \\
$-\mathrm{N}_{50}$ & $686,22 \mathrm{~b}$ & $316,56 \mathrm{~b}$ & $369,67 \mathrm{bc}$ & $53,54 \mathrm{c}$ & $0,86 \mathrm{a}$ \\
$\mathrm{C}_{2}$ & $410,44 \mathrm{c}$ & $119,44 \mathrm{c}$ & $290,56 \mathrm{c}$ & $66,29 \mathrm{~b}$ & $0,33 \mathrm{c}$ \\
$-\mathrm{P}_{2}$ & $481,00 \mathrm{c}$ & $126,60 \mathrm{c}$ & $354,40 \mathrm{c}$ & $60,95 \mathrm{bc}$ & $0,38 \mathrm{c}$ \\
$-\mathrm{N}_{2}$ & $420,40 \mathrm{c}$ & $123,60 \mathrm{c}$ & $296,80 \mathrm{c}$ & $52,14 \mathrm{c}$ & $0,41 \mathrm{c}$ \\
\hline
\end{tabular}

$\mathrm{C}=56,1 \mathrm{mg} \mathrm{L}^{-1}$ de nitrogênio e $10,0 \mathrm{mg} \mathrm{L}^{-1}$ de fósforo, $-\mathrm{N}=6,5 \mathrm{mg} \mathrm{L}^{-1}$ de nitrogênio e $10,0 \mathrm{mg} \mathrm{L}^{-1}$ de fósforo, $-\mathrm{P}=56,1 \mathrm{mg}$ $\mathrm{L}^{-1}$ de nitrogênio e $2,0 \mathrm{mg} \mathrm{L}^{-1}$ de fósforo. (50) equivale $50 \%$ de irradiância (2) equivale a $2 \%$ de irradiância. Letras comparam os dados dentro de uma mesma coluna.

aparecimento de clareiras (Whitmore 1998). irradiância dada (Osunkoya et al. 1994). E. Para isto, as espécies necessitam aclimatar-se edulis em baixa irradiância mostrou menor razão à variação de irradiância ocorrida. Aclimatação à variação na irradiância é dependente da capacidade da planta em alterar tanto a alocação de massa seca como a capacidade fotossintética, de maneira a obter o maior ganho de carbono na R:PA e maior RAF que plantas em irradiância mais alta, plasticidade esta que reflete um aumento potencial para a captura de luz e é importante para manter o crescimento e sobrevivência das plantas em baixa irradiância 
Tabela 3. Taxa média de crescimento relativo (TCR), taxa média de assimilação líquida (TAL) e razão média de área foliar (RAF) de plantas de Euterpe edulis dias crescendo a 50\% e 2\% da irradiância solar plena, irrigadas com solução nutritiva com alto e baixo teores de fósforo e nitrogênio.

Tratamento $\quad$ TCR $\left(\mathrm{mg} \mathrm{d}^{-1}\right) \quad$ TAL $\left(\mathrm{mg} \mathrm{cm}^{-2} \mathrm{~d}^{-1}\right) \quad$ RAF $\left(\mathrm{cm}^{2} \mathrm{mg}^{-1}\right)$

\begin{tabular}{llll}
\hline $\mathrm{C}_{50}$ & $0,0105 \mathrm{a}$ & $0,1190 \mathrm{a}$ & $0,0882 \mathrm{~b}$ \\
$-\mathrm{P}_{50}$ & $0,0092 \mathrm{~b}$ & $0,0942 \mathrm{~b}$ & $0,0966 \mathrm{~b}$ \\
$-\mathrm{N}_{50}$ & $0,0087 \mathrm{~b}$ & $0,0966 \mathrm{~b}$ & $0,0907 \mathrm{~b}$ \\
$\mathrm{C}_{2}$ & $0,0050 \mathrm{c}$ & $0,0412 \mathrm{c}$ & $0,1240 \mathrm{a}$ \\
$-\mathrm{P}_{2}$ & $0,0056 \mathrm{c}$ & $0,0550 \mathrm{c}$ & $0,1310 \mathrm{a}$ \\
$-\mathrm{N}_{2}$ & $0,0051 \mathrm{c}$ & $0,0510 \mathrm{c}$ & $0,1220 \mathrm{a}$ \\
\hline
\end{tabular}

$\mathrm{C}=56,1 \mathrm{mg} \mathrm{L}^{-1}$ de nitrogênio e $10,0 \mathrm{mg} \mathrm{L}^{-1}$ de fósforo, $-\mathrm{N}=6,5 \mathrm{mg} \mathrm{L}^{-1}$ de nitrogênio e $10,0 \mathrm{mg} \mathrm{L}^{-1}$ de fósforo, $-\mathrm{P}=56,1 \mathrm{mg}$ $\mathrm{L}^{-1}$ de nitrogênio e $2,0 \mathrm{mg} \mathrm{L}^{-1}$ de fósforo. (50) equivale $50 \%$ de irradiância e (2) equivale a $2 \%$ de irradiância. O intervalo de tempo utilizado para o cálculo da TCR e TAL foi entre 74 e 207 dias de crescimento nos diferentes tratamentos. Letras comparam os dados dentro de uma mesma coluna.

Tabela 4. Eficiência na utilização de fósforo (EUP) e de nitrogênio (EUN) em plantas de Euterpe edulis após 207 dias crescendo a $50 \%$ e $2 \%$ de irradiância solar plena, irrigadas com com solução nutritiva com alto e baixo teores de fósforo e nitrogênio.

\begin{tabular}{lll}
\hline Tratamento & $\begin{array}{l}\text { EUP } \\
\text { mg massa seca / } \\
\text { mg do nutriente }\end{array}$ & EUN \\
\hline $\mathrm{C}_{50}$ & $457,01 \mathrm{a}$ & $77,27 \mathrm{~b}$ \\
$-\mathrm{P}_{50}$ & $473,50 \mathrm{a}$ & $72,37 \mathrm{~b}$ \\
$-\mathrm{N}_{50}$ & $428,32 \mathrm{a}$ & $87,90 \mathrm{a}$ \\
$\mathrm{C}_{2}$ & $370,73 \mathrm{~b}$ & $41,60 \mathrm{~d}$ \\
$-\mathrm{P}_{2}$ & $396,67 \mathrm{~b}$ & $47,60 \mathrm{~cd}$ \\
$-\mathrm{N}_{2}$ & $304,03 \mathrm{~b}$ & $53,30 \mathrm{c}$ \\
\hline
\end{tabular}

$\mathrm{C}=56,1 \mathrm{mg} \mathrm{L}^{-1}$ de nitrogênio e $10,0 \mathrm{mg} \mathrm{L}^{-1}$ de fósforo, $-\mathrm{N}=$ $6,5 \mathrm{mg} \mathrm{L}^{-1}$ de nitrogênio e $10,0 \mathrm{mg} \mathrm{L}^{-1}$ de fósforo, $-\mathrm{P}=56,1$ $\mathrm{mg} \mathrm{L}^{-1}$ de nitrogênio e $2,0 \mathrm{mg} \mathrm{L}^{-1}$ de fósforo. (50) equivale $50 \%$ de irradiância e (2) equivale a $2 \%$ de irradiância. Letras comparam os dados dentro de uma mesma coluna.

(Givnish 1988). Sob maior irradiância, E. edulis apresentou maior taxa de assimilação líquida de carbono, maior razão R:PA e menor RAF. O primeiro ajustamento, fisiológico, reflete a capacidade da espécie em adequar seu aparato fotossintético ao aumento de irradiância, mecanismo chave para a capacidade de aclimatação de plantas à alta irradiância
(Bungard et al. 2000). Os dois outros ajustamentos, morfológicos, aumento da razão R:PA e diminuição da RAF, levam, no primeiro caso, a maximizar a absorção de água e nutrientes para a maior demanda fotossintética e transpiratória e, no segundo caso a diminuir a área transpiratória em maiores irradiâncias (Claussen 1996). Os dados encontrados neste trabalho para plantas jovens de E. edulis em relação à variação na irradiância estão de acordo com resultados anteriores encontrados por Andrade et al. (1996) e indicam que plantas de E. edulis apresentam comportamento similar àquele encontrado para a maioria das espécies de florestas tropicais, ou seja, limitação do crescimento nas condições de luz de sub-bosque, mas com capacidade para manter nestas condições taxa de crescimento positiva, provavelmente devido à capacidade de ajustar sua morfologia para o aumento de captação de luz, e potencialidade para o aumento de crescimento com o aparecimento de clareiras, já que a espécie apresenta ajustamentos morfológicos e fisiológicos importantes para a aclimatação à irradiância mais alta.

Com relação à variação no suprimento de nitrogênio e fósforo, as plantas de E. edulis apresentaram dois tipos de comportamento. Sob alta irradiância, houve aumento da taxa de 
Tabela 5. Concentração (\%) e conteúdo (mg planta $\left.{ }^{-1}\right)$ de fósforo (P) e nitrogênio (N) em plantas de Euterpe edulis após 207 dias crescendo a $50 \%$ e $2 \%$ da irradiância solar plena, irrigadas com solução nutritiva com alto e baixo teores de fósforo e nitrogênio.

\begin{tabular}{lcccc}
\hline Tratamento & $\begin{array}{c}\mathrm{P} \\
\left(\%{ }^{1}\right)\end{array}$ & $\begin{array}{c}\text { P total } \\
\left(\mathrm{mg} \mathrm{planta}^{-1}\right)\end{array}$ & $\begin{array}{c}\mathrm{N} \\
(\%)\end{array}$ & $\begin{array}{c}\mathrm{N} \text { total } \\
\left(\mathrm{mg} \mathrm{planta}^{-1}\right)\end{array}$ \\
\hline $\mathrm{C}_{50}$ & $0,20 \mathrm{a}$ & $2,4 \mathrm{a}$ & $1,21 \mathrm{a}$ & $14,5 \mathrm{a}$ \\
$-\mathrm{P}_{50}$ & $1,6 \mathrm{~b}$ & $1,22 \mathrm{a}$ & $10,3 \mathrm{~b}$ \\
$-\mathrm{N}_{50}$ & $0,19 \mathrm{a}$ & $1,3 \mathrm{bc}$ & $0,96 \mathrm{~d}$ & $6,7 \mathrm{~d}$ \\
$\mathrm{C}_{2}$ & $0,20 \mathrm{a}$ & $0,8 \mathrm{~d}$ & $1,87 \mathrm{~b}$ & $7,5 \mathrm{c}$ \\
$-\mathrm{P}_{2}$ & $0,20 \mathrm{a}$ & $1,0 \mathrm{~cd}$ & $1,67 \mathrm{bc}$ & $8,0 \mathrm{c}$ \\
$-\mathrm{N}_{2}$ & $0,22 \mathrm{a}$ & $1,0 \mathrm{~cd}$ & $1,43 \mathrm{c}$ & $6,0 \mathrm{~d}$ \\
\hline
\end{tabular}

$\mathrm{C}=56,1 \mathrm{mg} \mathrm{L}^{-1}$ de nitrogênio e $10,0 \mathrm{mg} \mathrm{L}^{-1}$ de fósforo, $-\mathrm{N}=6,5 \mathrm{mg} \mathrm{L}^{-1}$ de nitrogênio e $10,0 \mathrm{mg} \mathrm{L}^{-1}$ de fósforo, $-\mathrm{P}=56,1 \mathrm{mg}$ $\mathrm{L}^{-1}$ de nitrogênio e $2,0 \mathrm{mg} \mathrm{L}^{-1}$ de fósforo. (50) equivale $50 \%$ de irradiância e (2) equivale a $2 \%$ de irradiância. Letras comparam os dados dentro de uma mesma coluna.

Tabela 6. Concentração de nitrogênio e fósforo (\%) em raiz e parte aérea de plantas de Euterpe edulis após 207 dias crescendo em dois níveis de luz e irrigadas com solução nutritiva com alto teores de nitrogênio e fósforo.

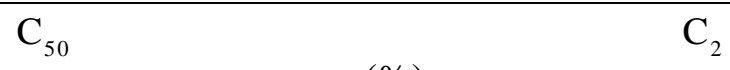

$(\%)$

\begin{tabular}{lllll}
\hline & Raiz & Parte Aérea & Raiz & Parte Aérea \\
Nitrogênio & $0,92 \mathrm{c}$ & $1,08 \mathrm{~b}$ & $0,70 \mathrm{~d}$ & $1,80 \mathrm{a}$ \\
Fósforo & $0,16 \mathrm{~b}$ & $0,12 \mathrm{c}$ & $0,29 \mathrm{a}$ & $0,17 \mathrm{~b}$ \\
\hline
\end{tabular}

C=Solução nutritiva com $56,1 \mathrm{mg} \mathrm{L}^{-1}$ de nitrogênio e $10,0 \mathrm{mg} \mathrm{L}^{-1}$ de fósforo. (50) equivale $50 \%$ da irradiância solar plena e (2) equivale a $2 \%$ da irradiância solar plena. $m=$ massa. Letras comparam os dados entre colunas.

assimilação líquida de carbono e do crescimento em maior suprimento conjunto de nitrogênio e fósforo. Já, em menor irradiância, o maior suprimento destes nutrientes para plantas não influenciou a taxa de assimilação de carbono e o crescimento destas. Estes dois tipos de resposta ao maior suprimento de nitrogênio e fósforo sugerem que a variação natural destes nutrientes no campo tem pouca influência no crescimento e sobrevivência das plântulas desta espécie sob o dossel fechado da floresta, mas podem influenciar o crescimento e estabelecimento da espécie em condições de clareira, onde a irradiância é mais alta. Para espécies de dipterocarpáceas da floresta tropical asiática, Bungard et al. (2000) também encontraram que o crescimento das espécies é fortemente restringido pela baixa irradiância e sugerem que é improvável que em condições naturais a variação de nitrogênio afete o crescimento e sobrevivência destas espécies sob o dossel fechado da floresta. A resposta de plantas de E. edulis ao aumento do suprimento de nutrientes em alta irradiância, observado também em outras espécies florestais (Thompson et al. 1992; Elliot \& White 1994; Minotta \& Pinzauti 1996; Gunatilleke et al. 1997, Bungard et al. 2000), é considerada uma resposta vantajosa na competitividade potencial destas espécies quando do aparecimento de clareiras, já que neste ambiente ocorre aumento de irradiância com conseqüente aumento na disponibilidade de nutrientes devido à rápida mineralização da matéria orgânica no solo (Minotta \& Pinzauti 1996).

Bungard et al. (1998) verificaram para Clematis vitalba e Elliot \& White (1994), para 
Pinus resinosa, que suprimento adicional de nitrogênio foi suficiente para aumentar a biomassa das plantas em alta irradiância, enquanto suprimento adicional de fósforo não, concluindo que a disponibilidade de nitrogênio é o principal nutriente limitante para o crescimento destas espécies em alta irradiância. Entretanto, o crescimento em biomassa de E. edulis em maior irradiância só foi afetado pelo suprimento conjunto de nitrogênio e de fósforo, sugerindo que em condições naturais a disponibilidade de ambos os nutrientes influenciam o crescimento desta espécie em alta irradiância.

Usualmente, uma restrição de nutrientes leva ao aumento de alocação de massa seca para a raiz em relação à parte aérea em condições não limitantes de luz (Chapin 1980), embora haja exceções (Gunatilleke et al. 1997, Cordero 2000). Em E. edulis, a disponibilidade de nitrogênio ou fósforo não influenciou a alocação de matéria seca entre raiz e parte aérea. Esta falta de plasticidade em alterar a distribuição de biomassa com aumento de nutrientes pode estar relacionada à concentração de nutrientes testada e não a um comportamento inerente à espécie, já que em outro estudo com E. edulis, um aumento na oferta de nutrientes através de aplicação de solução nutritiva ao substrato de crescimento das plantas, em concentração de nitrogênio e fósforo cerca de quatro vezes mais elevada que as experimentadas neste trabalho, levou à diminuição da razão raiz:parte aérea (Venturi \& Paulilo 1998).

Plantas de E. edulis foram mais eficientes na utilização de nitrogênio e fósforo quando a irradiância foi mais alta, comportamento similar ao de outras espécies (Elliot \& White 1994; Minotta \& Pinzauti 1996), e que possibilita a elas aproveitarem melhor a nutrição do solo quando do aparecimento de clareiras. A maior eficiência na utilização de nitrogênio em baixa oferta deste nutriente observada em E. edulis sob alta ou baixa irradiância pode aumentar a capacidade das plantas desta espécie em competirem com outras espécies em ambientes com baixos níveis deste nutriente.

Os resultados encontrados em E. edulis para a concentração, conteúdo total e distribuição de nutrientes entre raiz e parte aérea seguem o padrão observado para outras espécies, ou seja: a) a concentração de nitrogênio foi menor em plantas sob alta irradiância, fato usual em plantas sob alta irradiância, decorrente do maior investimento de carbono para a parte estrutural devido ao maior crescimento, resultando em maior diluição dos nutrientes (Johnson et al. 1997), b) o conteúdo total de nitrogênio e fósforo em plantas com maior suprimento destes nutrientes foi maior sob alta irradiância, característica usual em plantas nesta condição, já que o maior crescimento dado pela maior irradiância demanda maior quantidade de nutrientes (Minota \& Pinzauti 1996) e c) a maior concentração de nitrogênio encontrou-se na parte aérea, dado este relacionado a investimentos em compostos para o processo fotossintético que ocorre na parte aérea da planta (Thompson et al. 1992).

Os dados encontrados para E. edulis permitem sugerir que para esta espécie: 1) é improvável que a variação natural de nitrogênio e fósforo limite o crescimento de plântulas sob o dossel da floresta; o nivel de irradiância parece ser o principal fator limitante do crescimento de plantas jovens neste ambiente, 2) o desempenho de plantas jovens pode ser favorecido pelo aparecimento de clareiras em função da plasticidade destas plantas em aumentar tanto a eficiência na utilização de nutrientes como a taxa de assimilação líquida de carbono em maior irradiância, 3) a maior eficiência na utilização de nitrogênio em menor oferta deste nutriente pode aumentar a competitividade de plantas jovens em ambientes com baixa oferta deste nutriente e 4) em alta irradiância, tanto a baixa disponibilidade de fósforo quanto a de nitrogênio pode inibir o crescimento de plantas jovens no campo . 


\section{Agradecimentos}

Rafael Illenseer agradece ao CNPq a bolsa fornecida. Os autores agradecem aos revisores anônimos que contribuíram em muito para a melhoria deste trabalho e ao Laboratório de Análise de Solos da Universidade Federal do Rio Grande do Sul a análise dos teores de nutrientes nos tecidos vegetais.

\section{Referências bibliográficas}

Andrade, A. C. S.; Venturi, S. \& Paulilo, M. T. S. 1996. Efeito do tamanho da semente de Euterpe edulis Mart. sobre a germinação e crescimento inicial. Revista Brasileira de Sementes 18(2):150-157.

Banzato, D. A. \& Kronka, S. N. 1989. Experimentação agrícola. FUNEP, Jaboticabal.

Bungard, R. A; Morton, J. D.; McNeil, D. L. \& Daly, G. 1998. Effects of irradiance and nitrogen on Clematis vitalba establishment in a New Zealand lowland podocarp forest remnant. New Zealand Journal of Botany 36: 661-670.

Bungard, R. A.; Press, M. C. \& Scholes, J. D. 2000. The influence of nitrogen on rain forest dipterocarp seedlings exposed to a large increase in irradiance. Plant, Cell and Environment 23: 1183-1194.

Chapin, F. S. III. 1980. The mineral nutrition of wild plants. Annual Review of Ecology \& Systematic. 11: $261-285$

Clark, D. B.; Clark, D. A.; Rich, P. M; Weis, S. \& Oberbauer, S. F. 1996. Landscape-scale evaluation of understorey light and canopy structure: methods and application in a neotropical lowland rain forest. Canadian Journal of Forest Research 26: 747-757.

Claussen, J. W. 1996. Acclimation abilities of three tropical rainforest seedlings to an increase in light intensity. Forest Ecology and Management 80:245-255.

Cordero, R. A. 2000. Effect of two natural light regimes and nutrient addition on the forest herb Begonia decandra (Begoniaceae). Revista de Biologia Tropical 48: 579-586.

Elliott, K. \& White, A. S. 1994. Effects of light, nitrogen, and phosphorus on red seedling growth and nutrient use efficiency. Forest Science 40:47-58.

Givnish, T. J. 1988. Adaptation to sun and shade: a whole plant perspective. Australian Journal of Plant Physiology 15:93-106.

Gunatilleke, C. V. S.; Gunatilleke, I. A. U. N.; Perera, G. A. D.; Burslen, D. F. R. P.; Ashton, P. M. S. \& Ashton, P. S. 1997. Responses to nutrient addition among seedlings of eight closely related species of Shorea in Sri Lanka. Journal of Ecology 85:301-311.

Hunt, R. 1982. Plant growth curves: the functional approach to plant growth analysis. Edward Arnold Ltd., London.

Johnson, J. D.; Tognetti, R.; Michelozzi, M.; Pinzauti, S; Minotta, G. \& Borghetti, M. 1997. Ecophysiological responses of Fagus sylvatica seedlings to changing light conditions. II. The interaction of light environment and soil fertility on seedlings physiology. Physiologia Plantarum 101:124-134.

Kitajima, K. 1996. Ecophysiology of tropical tree seedlings. Pp. 559-597. In: S. S. Mulkey, R. L. Chazdon \& A. P. Smith (Eds) Tropical Forest Plant Ecophysiology. Chapman \& Hall, New York.

Koerselman, W. \& Meuleman A. F. M. 1996. The vegetation $\mathrm{N}: \mathrm{P}$ ratio: a new tool to detect the nature of nutrient limitation. Journal of Applied Ecology 33:1441-1450.

Minotta, G. \& Pinzauti, S. 1996. Effects of light and soil fertility on growth, leaf chlorophyll content and nutrient use efficiency of beech (Fagus sylvatica L.) seedlings. Forest Ecology and Management 86:61-67.

Osmond, C. B. \& Chow, W. S. 1988. Ecology of photosynthesis in the sun and shade: summary and prognostications. Australian Journal of Plant Physiology 15:107-122.

Osunkoya, O. O.; Ash, J. E.; Hopkins, M. S. \& Grahan, A. 1994. Influence of seed size and seedlings ecological attributes on shade-tolerance of rainforest tree species in northern Queensland. Journal of Ecology 82:149-163.

Peace, W. S. H. \& Grubb, P. J. 1982. Interaction of light and mineral nutrient supply in the growth of Impatiens parviflora. New Phytology 90:127-150.

Reis, A. Kageyama, P. Y.; Reis, M. S. dos \& Fantini, A. 1996. Demografia de Euterpe edulis Martius (Arecaceae) em uma floresta ombrófila densa montana, em Blumenau (SC). Sellowia 45/48:5-37.

Schachtman, D. P.; Reid, R. J. \& Ayling S. M. 1998. Phosphorus uptake by plants: from soil to cell. Plant Physiology 116:447-453.

Shaver, G. R. \& Melillo, J. M. 1984. Nutrient budgets of marsh plants: Efficiency concepts and relation 
to availability. Ecology 65:1491-1510.

Tedesco, J. M; Gianello, C.; Bissani, C. A.; Bohnen, H. \& Volkweiss, S. J. 1995. Análise do solo, plantas e outros materiais. Departamento de Solos, UFRGS, Porto Alegre.

Thompson, W. A.; Kriedermann, P. E. \& Chaig, I. E. 1992. Photosynthetic response to light and nutrients in sun-tolerant and shade-tolerant rainforest trees. I. Growth, leaf anatomy and nutrient content. Australian Journal of Plant Physiology 71:23-31.

Venturi, S. \& Paulilo, M. T. S. 1998. Esgotamento das reservas na semente de Euterpe edulis Mart. e efeito da nutrição mineral nas plântulas. Acta Botanica Brasilica 12:215-220.

Whitmore, T .C. 1998. An Introduction to Tropical Rain Forest, $2^{\text {nd }}$ edn. Oxford University Press, Oxford. 